Article

\title{
Preparation and Mechanical Properties of Photo-Crosslinked Fish Gelatin/Imogolite Nanofiber Composite Hydrogel
}

\section{Naozumi Teramoto *, Akihiko Hayashi, Kaori Yamanaka, Asako Sakiyama, Asuka Nakano and Mitsuhiro Shibata}

Department of Life and Environmental Sciences, Faculty of Engineering, Chiba Institute of Technology, 2-17-1 Tsudanuma, Narashino, Chiba 275-0016, Japan; E-Mails: akihiko.h06232@gmail.com (A.H.); kaori.y05232@gmail.com (K.Y.); asako.s04231@gmail.com (A.S.); asuka.n03231@gmail.com (A.N.); shibata@sky.it-chiba.ac.jp (M.S.)

* Author to whom correspondence should be addressed; E-Mail: teramoto-n@sea.it-chiba.ac.jp; Tel.: +81-47-478-0406; Fax: +81-47-478-0406.

Received: 14 September 2012; in revised form: 7 November 2012 / Accepted: 22 November 2012 / Published: 29 November 2012

\begin{abstract}
Fish gelatin (FG) extracted from sea bream scales was reacted with glycidyl methacrylate (GMA), and the product (FG-GMA) was used for photopolymerization using a radical photoinitiator in the presence or absence of imogolite nanofibers in the aqueous solution. The synthesis of FG-GMA was confirmed by ${ }^{1} \mathrm{H}$ NMR spectroscopy, and photopolymerization of FG-GMA was achieved successfully by irradiation with ultraviolet (UV) light for 3 min to yield translucent composite hydrogels. The concentration of FG-GMA varied from $10 \%$ to $30 \%$ without imogolite, and that of imogolite varied from $0 \%$ to $2.0 \%$. A microtomed gel sample was observed with a transmission electron microscope (TEM), and imogolite nanofibers were found to be dispersed finely in the gelatin matrix. Scanning electron microscope (SEM) observation of the lyophilized gel revealed that it had a porous morphology. Mechanical properties of hydrogels were measured by compression tests using a mechanical tester, and viscoelastic properties were measured using a rheometer. The mechanical strength and storage modulus of the hydrogel increased with an increase of imogolite.
\end{abstract}

Keywords: gelatin; fish scale; imogolite; nanofibers; hydrogel; photopolymerization; composite gel 


\section{Introduction}

Collagen is the main protein constructing connective tissues in vertebrate animals. Collagen is also a well-known biocompatible material and often used as an extracellular matrix (ECM) for regenerative tissue engineering [1-4]. Gelatin is denatured and partially degraded collagen extracted by acidic, alkaline and/or hydrothermal processes; and it is also a candidate for ECM used in regenerative tissue engineering [5-8]. Usually, gelatin is extracted from the skin of domestic mammals, such as pigs, calves and cows. However, gelatin extracted from domestic mammals has a risk of spreading infectious diseases, including bovine spongiform encephalopathy (BSE). Marin gelatin, represented by fish gelatin, is an alternative to mammalian gelatin and expected to lower this risk [9-11]. The largest advantage of marine gelatin is that it is inexpensively available by extraction from seafood processing wastes. Gelatin and collagen are the major polymer products from skin, scales and bones of fishes in the seafood processing industry.

Collagen has a triple-stranded helix structure, and the structure partially remains in gelatin. The partial triple-stranded helix structure in many fish gelatins, however, is denatured in the aqueous solution at room temperature, because the denaturing temperature of fish collagen is lower [12]. This means that such fish gelatin is not gelling, but soluble in water at room temperature. The denaturation, as well as partial degradation, causes the weakness in mechanical properties of fish gelatin, and it has limited its application fields. Some research groups reported the reinforcement of gelatin materials [13-25]. To achieve the reinforcement of gelatin materials, they have often adopted strategies of crosslinking and/or compositing with other materials. Yadav et al. reported preparation of gelatin gel assembled with hydroxyapatite reinforced by multiwalled carbon nanotubes for artificial bone grafting applications [26].

Recently, several high-performance hydrogels, a double network gel [27], a topological gel [28], a nanocomposite gel [29] and a tetra-PEG gel [30], have been developed. Among these, the technique for the nanocomposite gel can be easily applied to various gels. We were inspired by the nanocomposite gel, and decided to prepare nanofiber-reinforced fish gelatin gel using imogolite as nanofibers. Imogolite is often seen in the clay fraction of soils derived from glassy volcanic ashes [31]. It is a hydrated aluminosilicate polymer with a tubular structure: An external diameter of $c a .2 \mathrm{~nm}$, an internal diameter of $c a .1 \mathrm{~nm}$ and a length from several hundred nanometers to several micrometers. We have already investigated the interaction between imogolite and type I collagen from calf skin and found that collagen was closely bound to imogolite through the electrostatic interaction at $\mathrm{pH}=4$ to $\mathrm{pH}=8$ [32]. Therefore, gelatin has a great chance of interacting with imogolite. While collagen from calf skin precipitates in the presence of imogolite, fish gelatin does not precipitate in the presence of imogolite. Most recently, Shikinaka et al. reported on imogolite-reinforced acrylamide gel [33]. They found a great reinforcing effect for imogolite. Reinforcement of polymer materials with imogolite was also reported by Takahara's group [34-36]. Liu et al. used halloysite, another clay nanotube, to prepare the nanocomposite hydrogel with high equilibrium degree of swelling [37].

Collagen and gelatin from mammalian sources are less soluble in neutral water at room temperature and easily become hydrogel. On the other hand, fish gelatin is soluble in water, and we should formulate a strategy for gelation of fish gelatin. Chiou et al. reported crosslinking of cold water fish gelatins by glutaraldehyde and genipin [16]. Kim and Uyama reported enzymatic crosslinking of cold 
water fish gelatin using transglutaminase [17]. Bhat and Karpin reported slight crosslinking by ultraviolet light irradiation [15]. In the present study, we formulated a strategy of crosslinking fish gelatin carrying methacrylate groups by UV irradiation in the presence of a radical photoinitiator. Fish gelatin was first reacted with glycidyl methacrylate (GMA), and the pendant methacrylate groups were used for radical photopolymerization (Scheme 1). Considering future applications for making 3D-shaped materials for cell culturing, as an example, photopolymerization is one of the desirable candidates for gelation methods for the purpose of making designed objects from fish gelatin. Photoencapsulation of chondrocytes in poly(ethyleneoxide) gel using methacrylate groups was reported by Elisseeff et al. [38]. More recently, Chou et al. evaluated photo-crosslinked alginate hydrogel in vivo for matrix accumulation by nucleus pulposus cells, and they proved the safety of photopolymerization of methacrylate groups in the presence of vital cells [39]. We examined the effect of the addition of imogolite on the mechanical and rheological properties.

Scheme 1. Preparation and photopolymerization of fish gelatin (FG) modified with GMA.

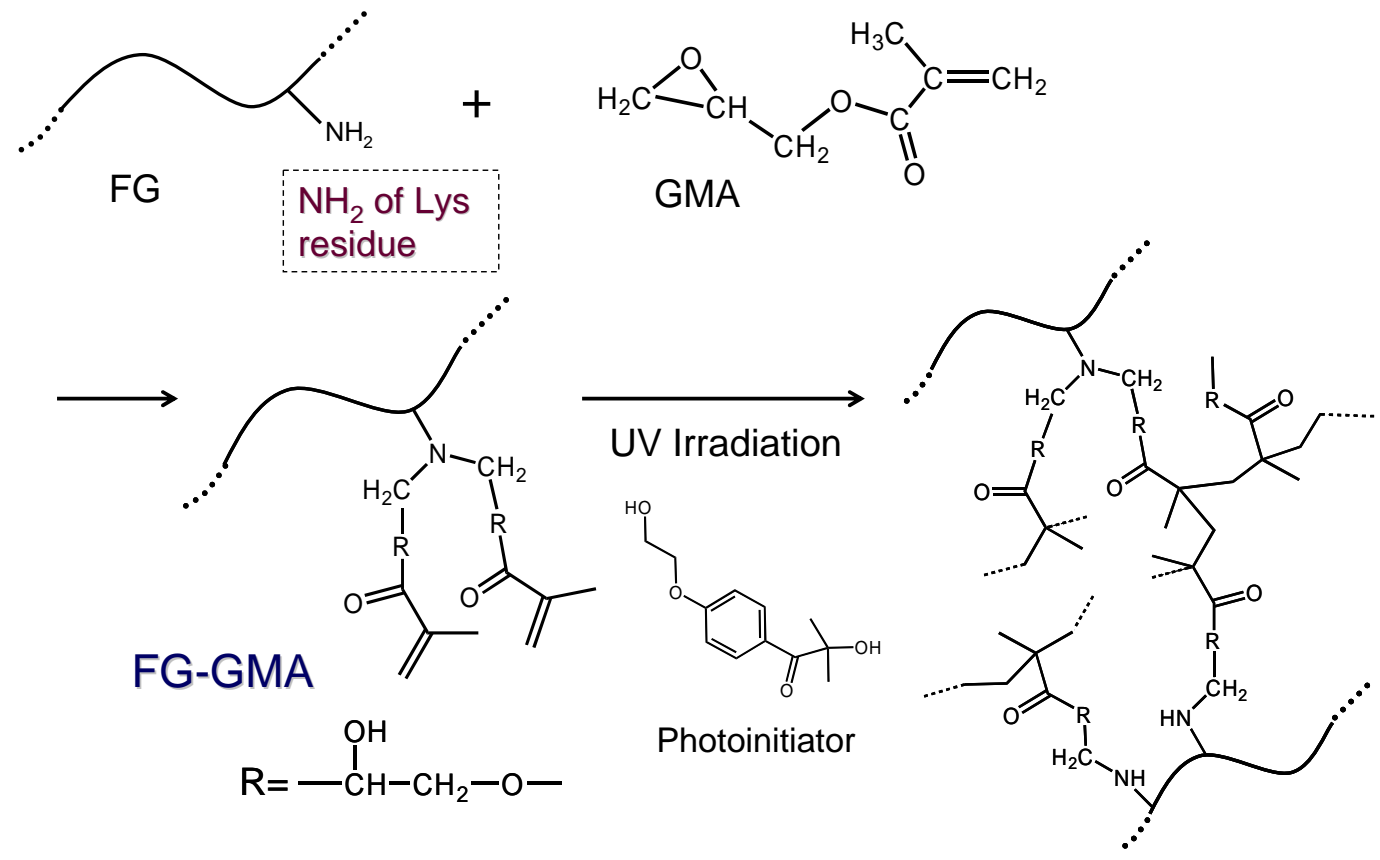

\section{Experimental}

\subsection{Materials}

Fish gelatin ( $M_{\mathrm{n}} 21,000 \mathrm{~g} / \mathrm{mol}$ and $M_{\mathrm{w}} 29,000 \mathrm{~g} / \mathrm{mol}$ measured by GPC with light scattering), which was extracted from the scales of red sea bream with hot water, was supplied by Kanemoto Kaisan Co., Ltd. (Chiba, Japan). Aluminum (III) chloride hexahydrate and glycidylmethacrylate (GMA) was purchased from Kanto Chemical Co., Inc. (Tokyo, Japan); and tetrasodium monosilicate n-hydrate (Si $22 \%$ ) was purchased from Wako Pure Chemical Industries, Ltd. (Osaka, Japan). 2-Ethyl-4-methylimidazole was purchased from Tokyo Chemical Industry Co., Ltd. (Tokyo, Japan). These chemical reagents were used as received. Irgacure 2959, 2-hydroxy-1-[4-(hydroxyethoxy)phenyl]-2-methyl-1-propanone, was kindly provided from Ciba Specialty Chemicals K. K. (Tokyo, Japan) and used as received. Ultra pure 
water (electric resistance $>18 \mathrm{M} \Omega \cdot \mathrm{cm}^{-1}$ ) used for gel preparation was obtained through Milipore Direct-Q and used for preparation of imogolite and hydrogel.

\subsection{Synthesis of Methacrylate-Modified Fish Gelatin (FG-GMA)}

Fish gelatin from red sea bream (FG) $(2.1 \mathrm{~g})$ was dissolved in $20 \mathrm{~mL}$ of dimethylsulfoxide (DMSO), and 2-ethyl-4-methylimidazole (0.2 g) was added. After $8.7 \mathrm{~mL}$ of GMA was added dropwise to the solution, the solution was stirred at $800 \mathrm{rpm}$ for $24 \mathrm{~h}$ at $28 \pm 1{ }^{\circ} \mathrm{C}$ using EYELA ChemiStation PPS-5510 personal organic synthesizer (Tokyo Rikakikai Co., Ltd.). After the reaction, the solution was poured dropwise into excess ethanol, and the mixture was stirred for $2 \mathrm{~h}$ at room temperature. The mixture was filtered with filter paper, and the product on the filter paper was washed with ethanol. To remove the residual volatile impurities, the product was dissolved in $50 \mathrm{~mL}$ of ultra pure water and lyophilized for 3 days to yield white powder (FG-GMA, yield 71\%).

\subsection{Synthesis of Imogolite}

Imogolite was synthesized by the method developed by Suzuki et al. [40] as follows: to prepare the reactant solutions, $3.35 \mathrm{~g}$ of tetrasodium monosilicate $\mathrm{n}$-hydrate $(\mathrm{Si} \sim 22 \%)(0.012 \mathrm{~mol})$ was dissolved in $200 \mathrm{~mL}$ of water; and $7.24 \mathrm{~g}$ of aluminum chloride hexahydrate $(0.030 \mathrm{~mol})$ was dissolved in $200 \mathrm{~mL}$ of water. To the solution of $\mathrm{AlCl}_{3}$ was added $2 \mathrm{Na}_{2} \mathrm{O} \cdot \mathrm{SiO}_{2}$ solution dropwise and stirred for $20 \mathrm{~min}$ at room temperature. Then $1 \mathrm{~N} \mathrm{NaOH}$ was added at a rate of $1 \mathrm{~mL} / \mathrm{min}$ using a syringe pump under stirring until the $\mathrm{pH}$ of the mixture reached 7.0. The mixture was centrifuged at a rate of $3500 \mathrm{rpm}$ for $10 \mathrm{~min}$ with polypropylene (PP) centrifuge tubes, and the supernatant was removed to obtain aluminosilicate gel. For the purpose of washing out the excess salt, enough water was added to the PP centrifuge tubes to suspend the product, and the suspension was poured into $400 \mathrm{~mL}$ of water in a $500 \mathrm{~mL}$ beaker. The suspension was stirred for $1 \mathrm{~h}$ at room temperature, and then centrifuged at a rate of $3500 \mathrm{rpm}$ for $10 \mathrm{~min}$, followed by removing the supernatant. This washing procedure was repeated three times. The precipitate, a translucent gel, was suspended in $2 \mathrm{~L}$ of water, and the $\mathrm{pH}$ of the suspension was adjusted to 4.0 with $0.5 \mathrm{~N} \mathrm{HCl}$. After stirring for 2 days at room temperature, the suspension became almost transparent. The suspension was divided into two 1 L PP screw capped bottles and aged for 2 days in an electric oven set at $105^{\circ} \mathrm{C}$. Then the suspension was lyophilized for 2 days to yield a white fibrous powder (yield 25\%). The X-ray diffraction (XRD) analysis also confirmed the synthesis of imogolite.

\subsection{Preparation of Gelatin/Imogolite Composite Hydrogel by Photoirradiation}

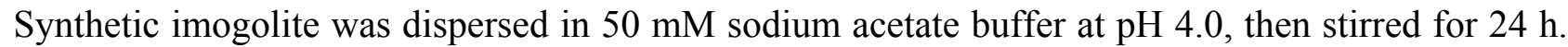
The dispersion was sonicated for $30 \mathrm{~s}$ at the power of level 4 (corresponding to $80 \mathrm{~W}$ output) and the frequency of $20 \mathrm{kHz}$ using a Branson Sonifier 250 ultrasonic homogenizer (Branson Ultrasonics Co.), and then FG-GMA was dissolved in the imogolite dispersion at the prescribed concentration. The morphology of imogolite nanofibers did not change during the sonication. To the mixture was added Irgacure 2959, a water-soluble radical photoinitiator, at the concentration of $0.1 \mathrm{wt} \%$. The mixed liquid sample was poured into a small Teflon container, and irradiated with UV light $\left(\sim 60 \mathrm{~mW} / \mathrm{cm}^{2}\right)$ 
using a Spotcure SP-7 UV irradiator (Ushio Inc.). In preparation of gel samples for compression tests, a Teflon container with an inner diameter of $12 \mathrm{~mm}$ and an inner height of $22 \mathrm{~mm}$ was used; and in preparation of gel samples for rheology measurement, a Teflon container with an inner diameter of $30 \mathrm{~mm}$ and an inner height of $10 \mathrm{~mm}$ was used. The height of the sample was $8 \mathrm{~mm}$ for the compression test, and $1.7 \mathrm{~mm}$ for the rheology measurement. The gel samples for compression tests were used as prepared; and the gel samples for rheology measurement were cut out using a pipe punch with an inner diameter of $20 \mathrm{~mm}$. To remove light of wavelength shorter than $300 \mathrm{~nm}$, the irradiation was carried out through a glass plate of $1 \mathrm{~mm}$ thickness.

\subsection{Characterization}

X-ray diffraction (XRD) analysis was performed at ambient temperature on a Rigaku RINT-2100 $\mathrm{X}$-ray diffractometer at a scanning rate of $1.0^{\circ} / \mathrm{min}$ using $\mathrm{Cu} \mathrm{K} \alpha$ radiation (wavelength, $\lambda=0.154 \mathrm{~nm}$ ) at $40 \mathrm{kV}$ and $14 \mathrm{~mA}$. Imogolite was analyzed in powder form. Proton nuclear magnetic resonance $\left({ }^{1} \mathrm{H} \mathrm{NMR}\right)$ spectra were recorded on a Bruker AV-400 (400 MHz) using DMSO- $d_{6}$ and $\mathrm{D}_{2} \mathrm{O}$ as a solvent.

The surface morphology of lyophilized gel samples was observed by a Hitachi S-4700 field emission scanning electron microscope (FE-SEM); the accelerating voltage was $1 \mathrm{kV}$ or $5 \mathrm{kV}$; and the samples were coated with gold prior to observation. The nanodispersion of imogolite in the composite gel samples was observed by a Hitachi H-7100FA transmission electron microscope (TEM). The accelerating voltage was $100 \mathrm{kV}$. The wet hydrogel sample was sectioned using a cryomicrotome, and the resulting ultrathin section was supported on a grid followed by drying in the pre-evacuation chamber of the TEM.

The compression test was carried out by a Shimadzu EZ-S tabletop universal tester with a $100 \mathrm{~N}$ load cell at a crosshead speed of $1 \mathrm{~mm} / \mathrm{min}$ using cylindrical specimens with a diameter of $12 \mathrm{~mm}$ and a height of $8 \mathrm{~mm}$. In each case, five specimens were tested and the average values were calculated. The dynamic viscoelasticity of the hydrogel was measured by a DAR-100 rheometer (Rheologica Instruments) equipped with a plate geometry with a diameter of $20 \mathrm{~mm}$. The storage and loss moduli $\left(G^{\prime}\right.$ and $\left.G^{\prime \prime}\right)$ were determined as a function of frequency under the condition of a linear viscoelastic response at $25^{\circ} \mathrm{C}$.

\section{Results and Discussion}

\subsection{Synthesis of Methacrylate-Modified Fish Gelatin (FG-GMA)}

The gelatin we used in the present study was extracted from scales of sea bream, and its molecular weight was lower than that of native fish collagen, because of hydrolysis during extraction with water at high temperature and high pressure. The fish gelatin, which is soluble in water and DMSO at room temperature, was reacted with GMA in DMSO in the presence of a base catalyst. After the purification and lyophilization, the dried white cake, which is soluble in water and DMSO, was obtained. Figure 1 shows the ${ }^{1} \mathrm{H}$ NMR spectra of fish gelatin (FG) and the product. Most signals in the spectrum of the product coincide with those of FG, except two signals corresponding to unsaturated methacrylate groups. These two signals were seen at $6.1 \mathrm{ppm}$ and $5.7 \mathrm{ppm}$. The signal of methyl protons of methacrylate groups was observed at $1.9 \mathrm{ppm}$. Considering that two GMA molecules generally react 
with one amino group of a Lys residue present in FG, the extent of the reaction can be calculated from the intensity of the signals and the Lys content in FG $(2.83 \mathrm{~mol} \%)$. The extent of the reaction calculated from ${ }^{1} \mathrm{H}$ NMR was $28 \%$.

Figure 1. ${ }^{1} \mathrm{H}$ NMR spectra of (a) FG; (b) GMA; and (c) the product (FG-GMA).

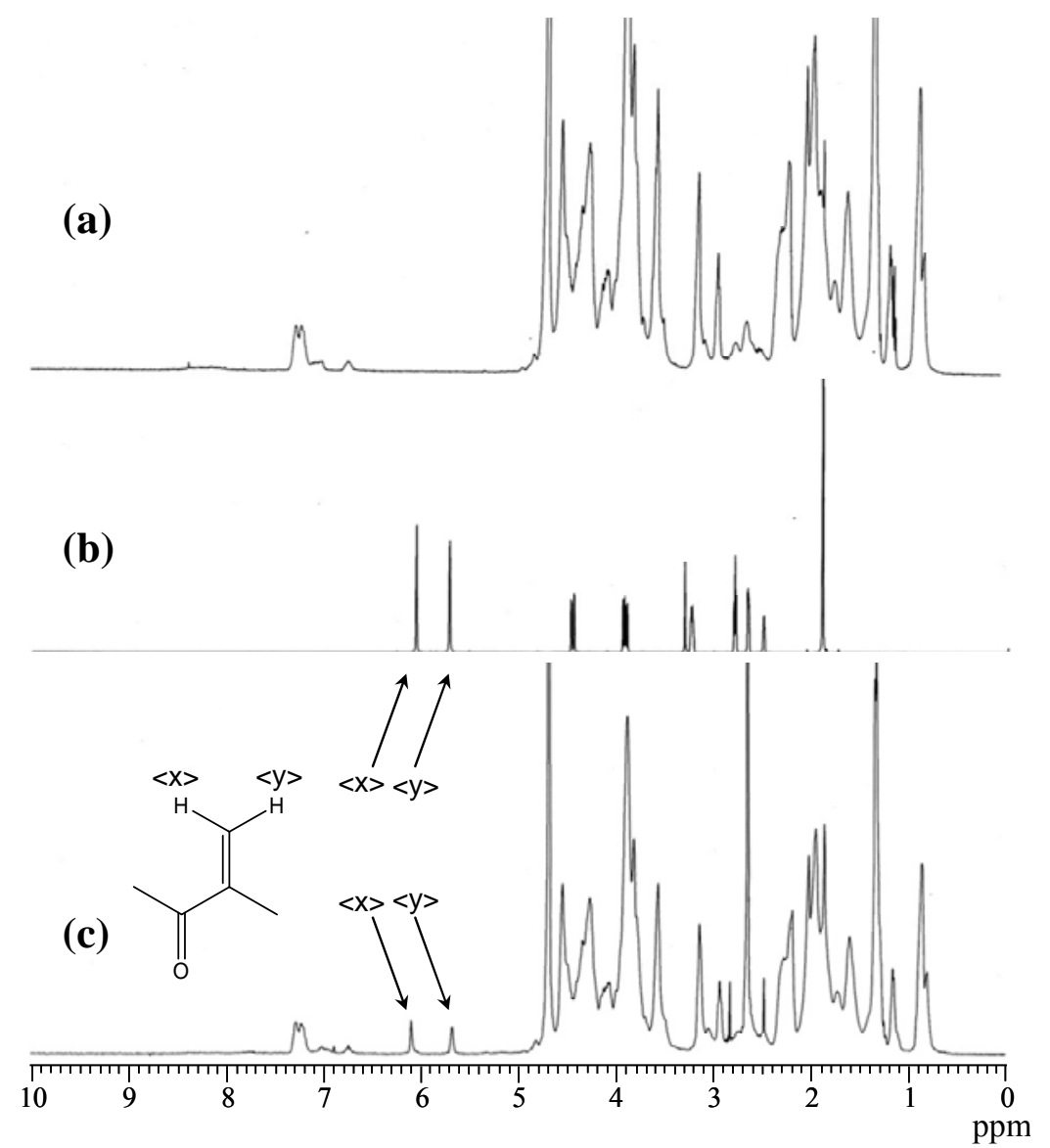

\subsection{Preparation of Gelatin/Imogolite Composite Hydrogel by Photoirradiation}

Imogolite synthesized in our laboratory was dispersed only in acidic buffer solution, and we used sodium acetate buffer $(\mathrm{pH} 4.0)$ to prepare the hydrogel. FG-GMA was dissolved in the imogolite dispersion at the concentration of $10 \%, 20 \%$ or $30 \%$ by weight. The final concentration of imogolite was varied from $0.2 \%$ to $2.0 \%$ against the whole weight of the hydrogel. Hydrogel samples were designated as "FG X-Imo Y", where $\mathrm{X}$ is concentration of FG-GMA and Y is imogolite content (in weight percentage). Among these samples, we could not prepare the FG30-Imo2.0 hydrogel sample, because the sample solution before UV irradiation became highly viscous and resulted in inhomogeneous gelation.

During photopolymerization, the sample solution was irradiated repeatedly at interval of $15 \mathrm{~s}$ irradiation, accompanied by $10 \mathrm{~s}$ cooling to prevent the solution from heating. The total irradiation time was $3 \mathrm{~min}$ for each sample. After irradiation with UV, a self-standing hydrogel was obtained. In the absence of imogolite, we obtained a semi-transparent hydrogel; and the transparency decreased with an increase of imogolite content (Figure 2). However, the transparency and turbidity did not change when imogolite content was $0.6 \%$ and more. The turbidity is due to the difference in the 
refractive index between imogolite and gelatin. The concentration of gelatin did not affect the transparency.

Figure 2. Digital photographs of composite hydrogels of FG and imogolite: (a) FG20; (b) FG20-Imo0.2; (c) FG20-Imo0.6; and (d) FG20-Imo2.0.

(a)
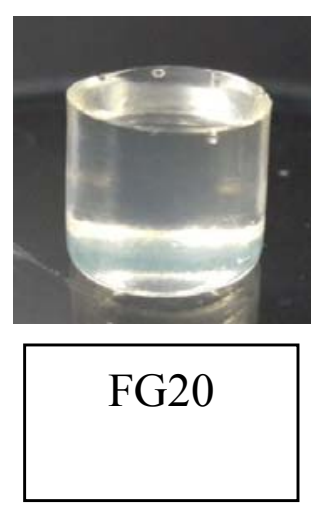

(b)

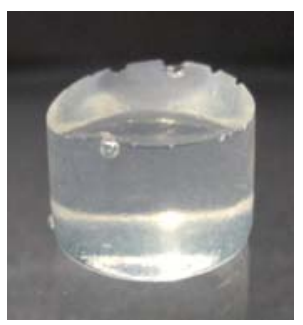

FG20- (c)

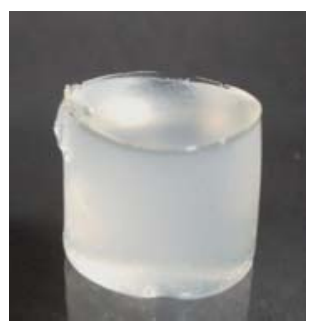

FG20-

Imo0.6 (d)

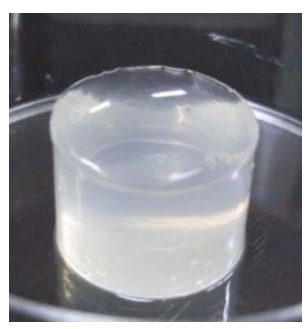

FG20-

Imo2.0

\subsection{Electron Microscopic Observation of Lyophylized Gelatin/Imogolite Composite Gel}

Surface morphology of the lyophilized gel was observed by FE-SEM and shown in Figure 3. All samples exhibited the porous morphology, and the pore size became smaller as imogolite content increased. The surface morphology of the lyophilized gel sample containing $2.0 \mathrm{wt} \%$ imogolite was different from the gel samples with lower imogolite content. Many pores were closed up by a matrixlike a wall, most probably due to deformation of the inner-side pores caused by rapid evacuation of water through small pores during the lyophilization process.

The dispersion state of imogolite nanofibers in the gel was observed by TEM. Figure 4 shows TEM photographs of FG20-imo0.4 and FG20-imo2.0. The TEM observation of FG20-imo0.4 revealed that imogolite nanofibers spread homogeneously in the FG matrix; and the result suggests that imogolite did not aggregate, but interact with FG. In our previous study, we reported on the complex products of imogolite with type I collagen from calf skin [32]. According to the previous study, the interaction between imogolite and type I collagen was so strong that precipitation occurred immediately by mixing type I collagen and imogolite, and we came to the conclusion that the major interaction was probably an electrostatic interaction. In the present study, however, no precipitation occurred when we mixed fish gelatin and imogolite. The different behavior is caused by the difference in molecular structures between type I collagen and fish gelatin, as well as the difference in the molecular weight. Type I collagen from mammals maintains a triple helix structure at room temperature, and its solubility is not so high. In contrast, fish gelatin derived from fish collagen is generally denatured at room temperature, resulting in an untwisting of the triple helices of peptide chains. The solubility of fish gelatin is high. Considering that imogolite was finely dispersed in the FG matrix, there exists weak interaction between imogolite and FG. On the other hand, the TEM photograph of FG20-imo2.0 showed fine dispersion and partial aggregation of imogolite. The result suggests that the interaction between imogolite and FG was not enough to disperse imogolite nanofiber at higher concentration. 
Figure 3. SEM photographs of lyophilized composite gels: (a) FG20; (b) FG20-Imo0.2; (c) FG20-Imo0.6; and (d) FG20-Imo2.0.

(a)

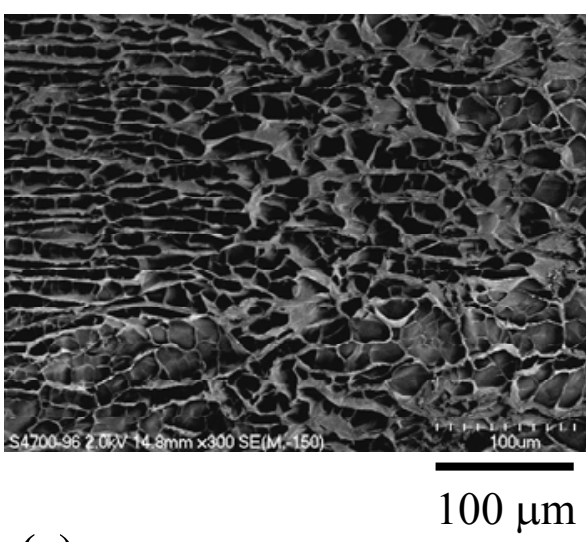

(c)

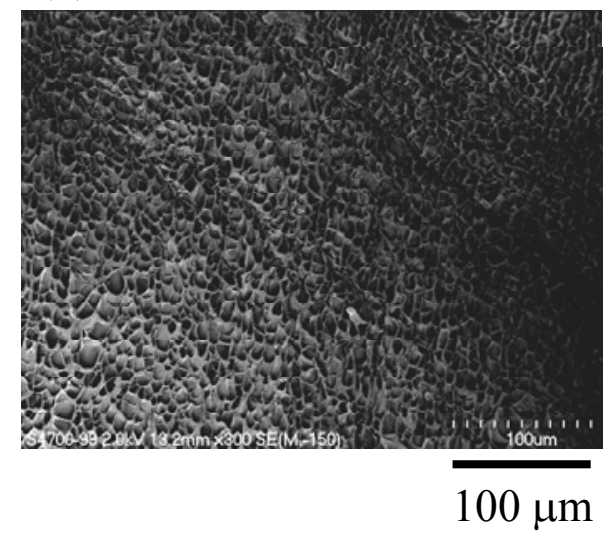

(b)

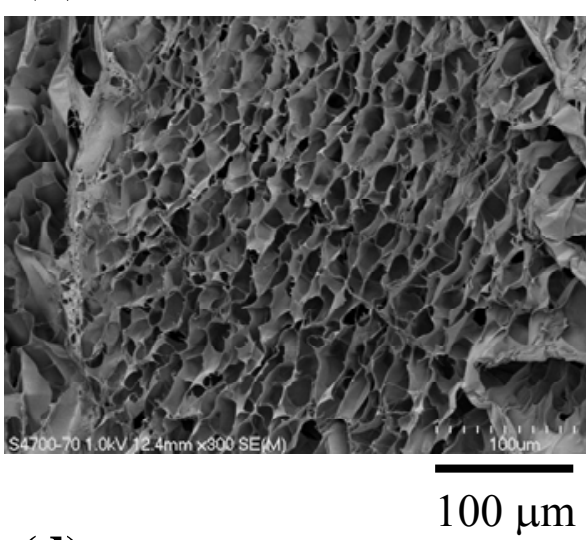

(d)

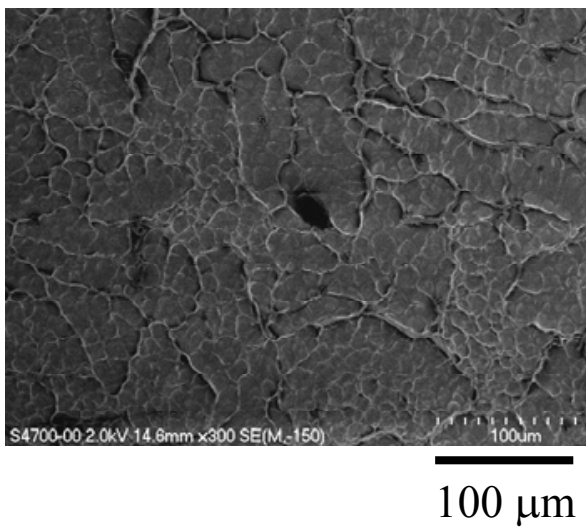

Figure 4. TEM photographs of composite gels sectioned using a cryomicrotome: (a) FG20-Imo0.4 and (b) FG20-Imo2.0.

(a)

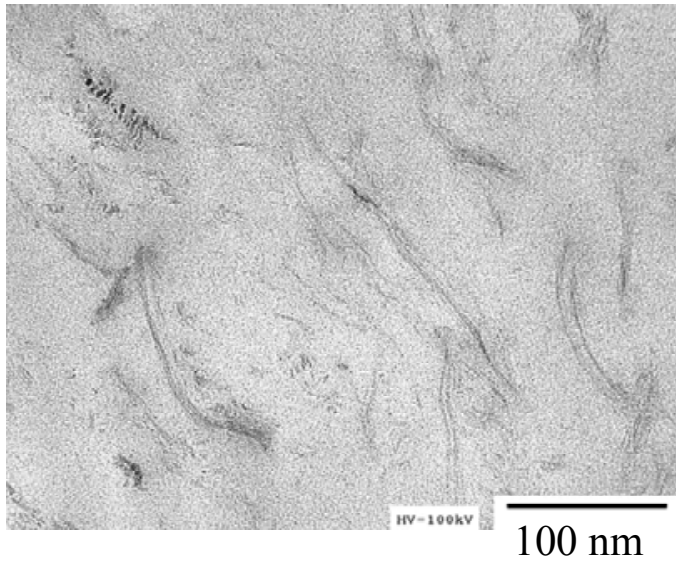

(b)

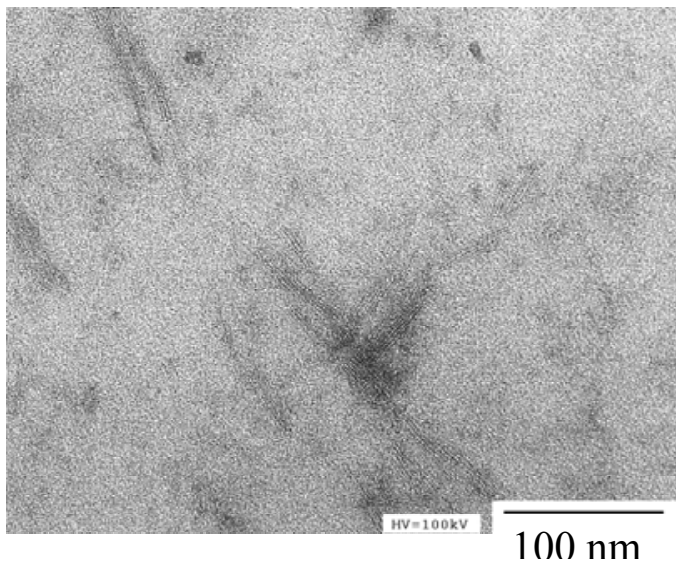

\subsection{Physical Properties of Gelatin/Imogolite Composite Hydrogel}

Mechanical properties of fish gelatin/imogolite composite hydrogels were measured by compression tests. Figure 5 shows the results of stress-strain curves in the compression tests of FG20 series. The compression stress at break (compression strength) increased by the addition of imogolite, 
and moderate reinforcement was observed at the imogolite content of $0.2 \mathrm{wt} \%$ and $0.6 \mathrm{wt} \%$. In contrast, a significant increase of compression strength was observed at the imogolite content of $2.0 \mathrm{wt} \%$, and the highest compression strength was $\sim 800 \mathrm{kPa}$. Aggregation of inorganic fillers in polymers generally reduces their improvement effect. In spite of the partial aggregation of imogolite in FG20-imo2.0, the compression strength increased compared with FG20-imo0.6. We suggest that imogolite nanofibers are so fine that they can keep the reinforcing effect, even if they aggregate partially.

Figure 5. Stress-strain curves of FG20 composite hydrogels in the compression test. Imogolite content was varied from $0 \%$ to $2.0 \%$.

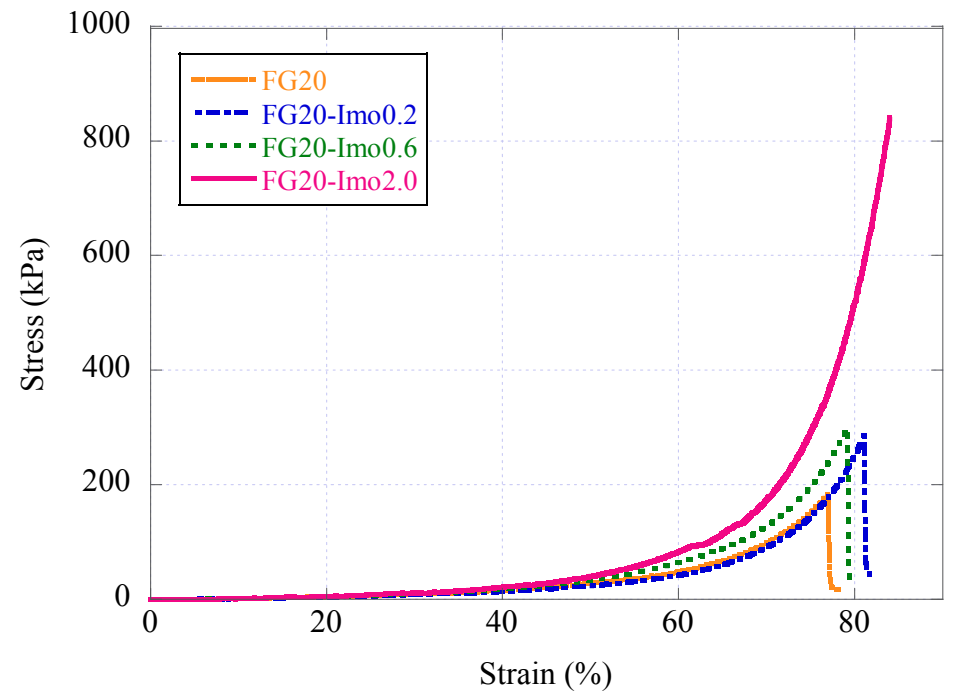

Figure 6a,b shows the results of stress-strain curves in the compression tests of FG10 series and FG30 series, respectively. While we observed moderate improvement of compression strength with imogolite for FG10 series, addition of imogolite diminished the compression strength for FG30 series. The compression strength of FG30-imo0.6 was lower than FG30 without imogolite. FG30-imo0.6 was a very brittle gel, and the strain at break of FG30-imo0.6 became low, resulting in lower toughness.

Figure 6. Stress-strain curves of FG10 and FG30 composite hydrogels in the compression test: (a) FG10 series and (b) FG30 series.

(a)

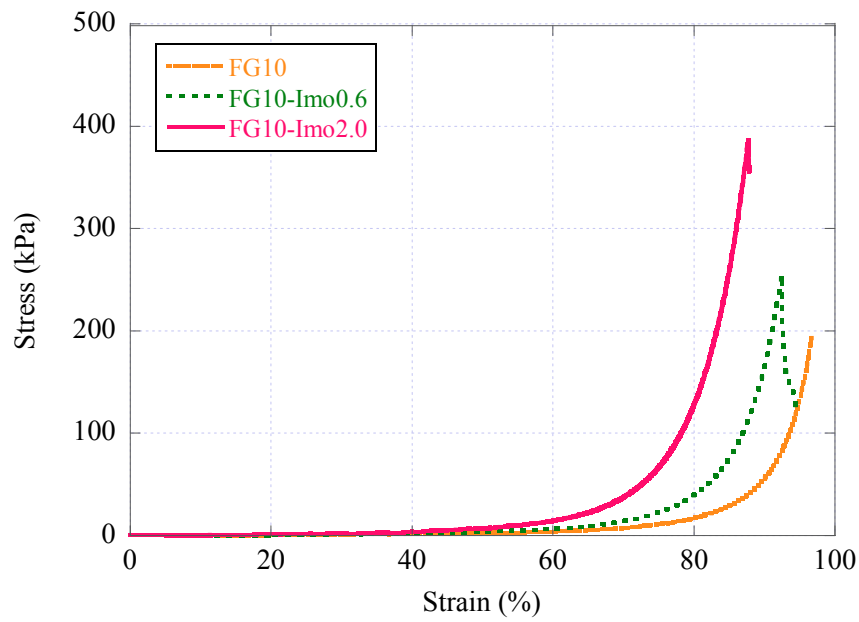

(b)

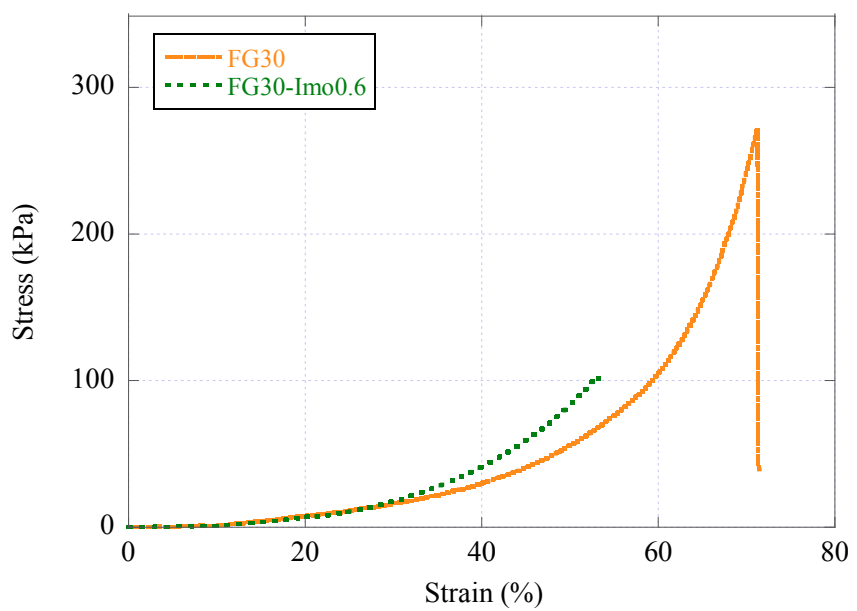


Figure 7 shows the viscoelasticity of fish gelatin/imogolite composite hydrogels in the frequency range of $0.1-10 \mathrm{~Hz}$. All samples show the typical gel behavior, with storage modulus $\left(\mathrm{G}^{\prime}\right)$ being higher than loss modulus $\left(G^{\prime \prime}\right)$ over the whole frequency range. Since $G^{\prime}$ relates to elasticity and $G^{\prime \prime}$ relates to viscosity, the comparison of $G^{\prime}$ with $G^{\prime \prime}$ is very important for the judgment between viscoelastic fluid and viscoelastic gel [41]. G' of photo-crosslinked samples was independent of oscillatory frequency and increased with an increase of imogolite content. The results indicate the effective reinforcement of fish gelatin gels with imogolite nanofibers. Though G" somewhat changed with frequency change, G" did not cross over $G^{\prime}$ for all samples. Regarding viscoelasticity of FG20, G" increased gradually, with an increase of frequency getting close to G'. The FG20 gel showed more viscous behavior at the higher frequency region than the lower frequency region, implying the partial existence of a loose network. In contrast, G" showed higher values at a lower frequency region for FG20-imo2.0. This type of viscoelastic behavior is often observed in the measurement of viscoelasticity of clay suspensions at higher concentration [42-44]. As imogolite content becomes higher, a three-dimensional network of imogolite nanofibers gradually emerges. The partial aggregation found in the TEM observation is considered to relate to this result.

Figure 7. Frequency dependency of storage modulus, G' (filled symbols), and loss modulus, G" (open symbols), for FG20 composite hydrogels at different imogolite content varied from $0 \%$ to $2.0 \%$.

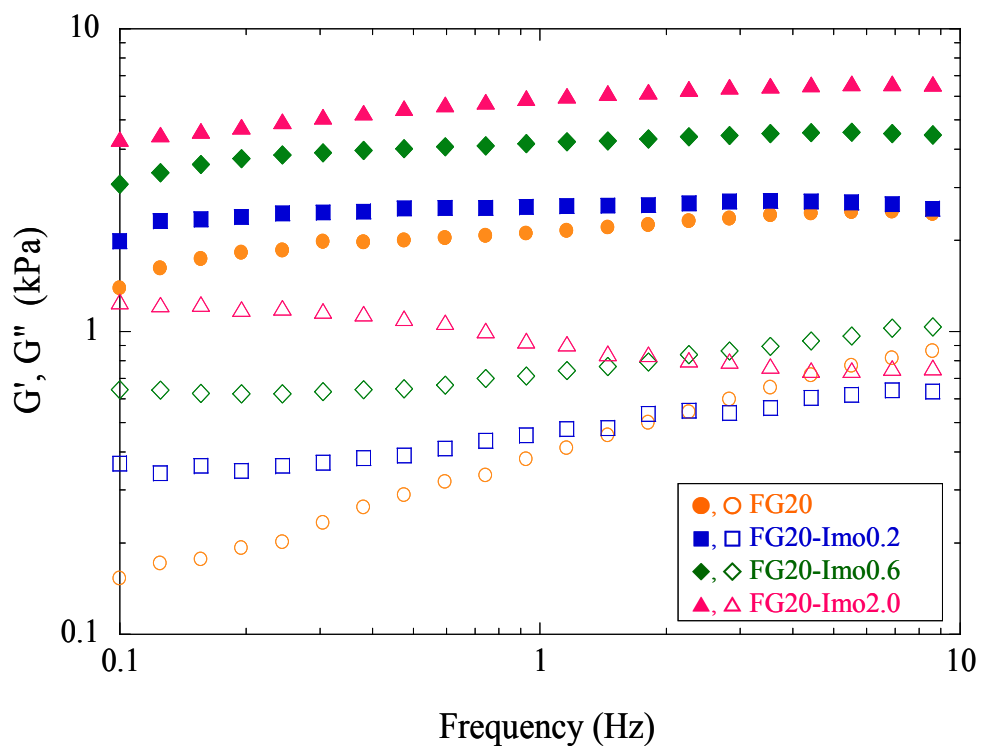

\section{Conclusions}

We proposed a novel approach for photopolymerization of fish gelatin and reinforcement with imogolite nanofibers. Fish gelatin modified with methacrylate groups was synthesized using glycidyl methacrylate as a modification reagent and was irradiated with UV light in the presence of imogolite and a radical photoinitiator to obtain translucent hydrogels. The morphology of the lyophilized hydrogel was revealed as highly porous by SEM observation. As a result of TEM observation, imogolite was found to be finely dispersed in the composite gel with $0.4 \%$ imogolite. In the composite gel with $2.0 \%$ imogolite, however, partial aggregation of imogolite was observed. In spite of the 
aggregation, the mechanical properties of the hydrogel were remarkably improved at the imogolite content of $2.0 \%$, when the concentration of the modified fish gelatin was $20 \%$. The hydrogel samples showed the viscoelastic properties typical of gel, with the storage modulus being higher than the loss modulus over the frequency range from $0.1 \mathrm{~Hz}$ to $10 \mathrm{~Hz}$.

\section{Acknowledgments}

The authors greatly acknowledge Masaya Suzuki, National Institute of Advanced Industrial Science and Technology (AIST), Japan, for giving advice for the synthetic procedures of imogolite. This research was supported by the Naito Foundation, Japan, especially at the preliminary report in an international conference.

\section{References}

1. Elsdale, T.; Bard, J. Collagen substrata for studies on cell behavior. J. Cell Biol. 1972, 54, 626-637.

2. Schor, S.L. Cell proliferation and migration on collagen substrata in vitro. J. Cell Sci. 1980, 41, $159-175$.

3. Strom, S.C.; Michalopoulos, G. Collagen as a substrate for cell growth and differentiation. Methods Enzymol. 1982, 82, 544-555.

4. Wallace, D.G.; Rosenblatt, J. Collagen gel systems for sustained delivery and tissue engineering. Adv. Drug Deliv. Rev. 2003, 55, 1631-1649.

5. Kang, H.-W.; Tabata, Y.; Ikada, Y. Fabrication of porous gelatin scaffolds for tissue engineering. Biomaterials 1999, 20, 1339-1344.

6. Kawai, K.; Suzuki, S.; Tabata, Y.; Ikada, Y.; Nishimura, Y. Accelerated tissue regeneration through incorporation of basic fibroblast growth factor-impregnated gelatin microspheres into artificial dermis. Biomaterials 2000, 21, 489-499.

7. Ito, A.; Mase, A.; Takizawa, Y.; Shinkai, M.; Honda, H.; Hata, K.-I.; Ueda, M.; Kobayashi, T. Transglutaminase-mediated gelatin matrices incorporating cell adhesion factors as a biomaterial for tissue engineering. J. Biosci. Bioeng. 2003, 95, 196-199.

8. Yao, C.-H.; Liu, B.-S.; Chang, C.-J.; Hsu, S.-H.; Chen, Y.-S. Preparation of networks of gelatin and genipin as degradable biomaterials. Mater. Chem. Phys. 2004, 83, 204-208.

9. Gómez-Guillén, M.C.; Pérez-Mateos, M.; Gópez-Estaca, J.; López-Caballero, E.; Giménez, B.; Montero, P. Fish gelatin: A renewable material for developing active biodegradable films. Trends Food Sci. Technol. 2009, 20, 3-16.

10. Karim, A.A.; Bhat, R. Fish gelatin: Properties, challenges, and prospects as an alternative to mammalian gelatins. Food Hydrocolloids 2009, 23, 563-576.

11. An, K.; Liu, H.; Guo, S.; Kumar, D.N.T.; Wang, Q. Preparation of fish gelatin and fish gelatin/poly(L-lactide) nanofibers by electrospinning. Int. J. Biol. Macromol. 2010, 47, 380-388.

12. Haug, I.J.; Draget, K.I.; Smidsrød, O. Physical and rheological properties of fish gelatin compared to mammalian gelatin. Food Hydrocolloids 2004, 18, 203-213.

13. Bigi, A.; Cojazzi, G.; Panzavolta, S.; Rubini, K.; Roveri, N. Mechanical and thermal properties of gelatin films at different degrees of glutaraldehyde crosslinking. Biomaterials 2001, 22, 763-768. 
14. Bigi, A.; Cojazzi, G.; Panzavolta, S.; Roveri, N.; Rubini, K. Stabilization of gelatin films by crosslinking with genipin. Biomaterials 2002, 23, 4827-4832.

15. Bhat, R.; Karim, A.A. Ultraviolet irradiation improves gel strength of fish gelatin. Food Chem. 2009, 113, 1160-1164.

16. Chiou, B.-S.; Avena-Bustillos, R.J.; Shey, J.; Yee, E.; Bechtel, P.J.; Imam, S.H.; Glenn, G.M.; Orts, W.J. Rheological and mechanical properties of cross-linked fish gelatins. Polymer 2006, 47, 6379-6386.

17. Kim, Y.-J.; Uyama, H. Biocompatible hydrogel formation of gelatin from cold water fish via enzymatic networking. Polym. J. 2007, 39, 1040-1046.

18. Yunoki, S.; Nagai, N.; Suzuki, T.; Munekata, M. Novel biomaterial from reinforced salmon collagen gel prepared by fibril formation and cross-linking. J. Biosci. Bioeng. 2004, 98, 40-47.

19. Kolodziejska, I.; Piotrowska, B. The water vapour permeability, mechanical properties and solubility of fish gelatin-chitosan films modified with transglutaminase or 1-ethyl-3-(3-dimethylaminopropyl) carbodiimide (EDC) and plasticized with glycerol. Food Chem. 2007, 103, 295-300.

20. Fallgatter, A.M.; Kim, J.H.; Fricton, J.; Hu, W.S. Mechanical properties and cytocompatibility of biomimetic hydroxyapatite-gelatin nanocomposites. J. Mater. Res. 2006, 21, 3090-3098.

21. Lee, W.-F.; Lee, S.-C. Effect of hydrotalcite on the swelling and mechanical behaviors for the hybrid nanocomposite hydrogels based on gelatin and hydrotalcite. J. Appl. Polym. Sci. 2006, 100, 500-507.

22. Rao, Y. Gelatin-clay nanocomposites of improved properties. Polymer 2007, 48, 5369-5375.

23. Wan, Y.Z.; Wang, Y.L.; Luo, H.L.; Cheng, G.X.; Yao, K.D. Carbon fiber-reinforced gelatin composites. I. Preparation and mechanical properties. J. Appl. Polym. Sci. 2000, 75, 987-993.

24. Zheng, J.P.; Li, P.; Ma, Y.L.; Yao, K.D. Gelatin/montmorillonite hybrid nanocomposite. I. Preparation and properties. J. Appl. Polym. Sci. 2002, 86, 1189-1194.

25. Teramoto, N.; Uchiumi, D.; Niikura, A.; Someya, Y.; Shibata, M. Polypeptide/layered silicate nanocomposites using fish-based collagen peptide: Effect of crosslinking and chain extension of the collagen peptide. J. Appl. Polym. Sci. 2007, 106, 4024-4030.

26. Yadav, S.K.; Bera, T.; Saxena, P.S.; Maurya, A.K.; Garbyal, R.S.; Vajtai, R.; Ramachandrarao, P.; Srivastava, A. MWCNTs as reinforcing agent to the hap-gel nanocomposite for artificial bone grafting. J. Biomed. Mater. Res. A 2010, 93, 886-896.

27. Gong, J.P.; Katsuyama, Y.; Kurokawa, T.; Osada, Y. Double-network hydrogels with extremely high mechanical strength. Adv. Mater. 2003, 15, 1155-1158.

28. Okumura, Y.; Ito, K. The polyrotaxane gel: A topological gel by figure-of-eight cross-links. Adv. Mater. 2001, 13, 485-487.

29. Haraguchi, K.; Takehisa, T. Nanocomposite hydrogels: A unique organic-inorganic network structure with extraordinary mechanical, optical, and swelling/de-swelling properties. Adv. Mater. 2002, 14, 1120-1124.

30. Sakai, T.; Matsunaga, T.; Yamamoto, Y.; Ito, C.; Yoshida, R.; Suzuki, S.; Sasaki, N.; Shibayama, M.; Chung, U.-I. Design and fabrication of a high-strength hydrogel with ideally homogeneous network structure from tetrahedron-like macromonomers. Macromolecules 2008, 41, 5379-5384. 
31. Cradwick, P.D.G.; Farmer, V.C.; Russell, J.D.; Masson, C.R.; Wada, K.; Yoshinaga, N. Imogolite, a hydrated aluminium silicate of tubular structure. Nat. Phys. Sci. 1972, 240, 187-189.

32. Nakano, A.; Teramoto, N.; Chen, G.; Miura, Y.; Shibata, M. Preparation and characterization of complex gel of type I collagen and aluminosilicate containing imogolite nanofibers. J. Appl. Polym. Sci. 2010, 118, 2284-2290.

33. Shikinaka, K.; Koizumi, Y.; Osada, Y.; Shigehara, K. Reinforcement of hydrogel by addition of fiber-like nanofiller. Polym. Adv. Technol. 2011, 22, 1212-1215.

34. Yamamoto, K.; Otsuka, H.; Wada, S.-I.; Sohn, D.; Takahara, A. Preparation and properties of [poly(methyl methacrylate)/imogolite] hybrid via surface modification using phosphoric acid ester. Polymer 2005, 46, 12386-12392.

35. Yamamoto, K.; Otsuka, H.; Wada, S.-I.; Sohn, D.; Takahara, A. Transparent polymer nanohybrid prepared by in situ synthesis of aluminosilicate nanofibers in poly(vinyl alcohol) solution. Soft Matter 2005, 1, 372-377.

36. Yah, W.O.; Yamamoto, K.; Jiravanichanun, N.; Otsuka, H.; Takahara, A. Imogolite reinforced nanocomposites: Multifaceted green materials. Materials 2010, 3, 1709-1745.

37. Liu, M.; Li, W.; Rong, J.; Zhou, C. Novel polymer nanocomposite hydrogel with natural clay nanotubes. Colloid Polym. Sci. 2012, 1-11.

38. Elisseeff, J.; McIntosh, W.; Anseth, K.; Riley, S.; Ragan, P.; Langer, R. Photoencapsulation of chondrocytes in poly(ethylene oxide)-based semi-interpenetrating networks. J. Biomed. Mater. Res. 2000, 51, 164-171.

39. Chou, A.I.; Akintoye, S.O.; Nicoll, S.B. Photo-crosslinked alginate hydrogels support enhanced matrix accumulation by nucleus pulposus cells in vivo. Osteoarthr. Cartil. 2009, 17, 1377-1384.

40. Suzuki, M.; Inukai, K.; Maeda, M. Synthesis of imogolite from inorganic solution influence of solution concentration on forming precursor for the synthesis of large quantities of imogolite. $J$. Vac. Soc. Jpn. 2006, 49, 29-33.

41. Liu, X.; Qian, L.; Shu, T.; Tong, Z. Rheology characterization of sol-gel transition in aqueous alginate solutions induced by calcium cations through in situ release. Polymer 2003, 44, 407-412.

42. Mourchid, A.; Lécolier, E.; van Damme, H.; Levitz, P. On viscoelastic, birefringent, and swelling properties of laponite clay suspensions: Revisited phase diagram. Langmuir 1998, 14, 4718-4723.

43. Paineau, E.; Michot, L.J.; Bihannic, I.; Baravian, C. Aqueous suspensions of natural swelling clay minerals. 2. Rheological characterization. Langmuir 2011, 27, 7806-7819.

44. Labanda, J.; Llorens, J. Rheology of Laponite colloidal dispersions modified by sodium polyacrylates. Colloids Surface A 2004, 249, 127-129.

(C) 2012 by the authors; licensee MDPI, Basel, Switzerland. This article is an open access article distributed under the terms and conditions of the Creative Commons Attribution license (http://creativecommons.org/licenses/by/3.0/). 